\title{
Maintenance Treatment With Vaginal Progesterone or Placebo Delayed Preterm Birth More Efficiently Than Intravenous Tocolysis Alone - A Randomized Controlled Trial
}

\section{Ylva Vladic Stjernholm ( $\nabla$ ylva.vladic-stjernholm@sll.se)}

Department of Women's and Children's Health, Karolinska University Hospital and Karolinska Institutet, SE-171 76 Stockholm, Sweden https://orcid.org/0000-0003-3414-6668

Giovanna Marchini

Women's and Children's Health, Karolinska University Hospital and Karolinska Institutet

\section{Research}

Keywords: Cervical ripening, gasterointestinal microbiome, infection, inflammation, preterm birth, progesterone

Posted Date: October 9th, 2020

DOI: https://doi.org/10.21203/rs.3.rs-87137/v1

License: (c) (i) This work is licensed under a Creative Commons Attribution 4.0 International License.

Read Full License 


\section{Abstract}

Objective To evaulate the efficacy of maintenance treatment with vaginal progesterone gel compared to placebo in women after the onset of preterm labor.

Material and Methods A randomized controlled trial at a university hospital in Sweden in 2009 - 18. Healthy women with singleton pregnancy and early preterm labor were randomized to daily progesterone gel $90 \mathrm{mg}(\mathrm{n}=29)$ or placebo $(n=29)$ after standard intravenous tocolysis. Women with intravenous tocolysis alone $(n=29)$ served as a reference group.

Results The latency to delivery was $58 \pm 34$ days with progesterone, $64 \pm 51$ days with placebo and $2 \pm 2$ days in the reference group ( $p<0.0001$ respectively). The rate of preterm birth $<34$ weeks was $34 \%$ after progesterone, $38 \%$ after placebo and $100 \%$ in the reference group (progesterone vs reference $p=0.01$ and placebo $v s$ reference $p=0.02$ ). The composite neonatal morbidity and length of neonatal intensive care were lower after progesterone and placebo compared to the reference group $(p<0.0001$ respectively).

Conclusion Maintenance treatment with vaginal progesterone gel or placebo delayed preterm birth more efficiently than intravenous tocolysis alone, suggesting an effect of the placebo gel rather than of progesterone. We conclude, that the placebo gel reinforced the physiological barrier at the uterine cervix which protects the pregnancy from pathogen invasion and uterine infection leading to preterm birth.

\section{Plain English Summary}

The global rate of preterm birth (PTB), the primary cause behind all neonatal, infant and child mortality up to 5 years age, is still $10 \%$. The multifactorial risk factors behind PTB include demographic and socioeconomic factors such as psychosocial stress, malnutrition, low and high maternal age, decidual bleeding, and in $30-60 \%$. uterine infection. Current tocolytic treatments do not prevent PTB, and trials on prophylactic progesterone $(\mathrm{P})$ or progestin treatments to delay PTB are inconclusive. The objective of this study was therefore to evaulate maintenance treatment with vaginal $\mathrm{P}$ gel compared to placebo in women after the onset of preterm labor. Healthy women with singleton pregnancy and early preterm labor were randomized to daily $P$ gel $90 \mathrm{mg}(n=29)$ or placebo $(n=29)$ after standard intravenous tocolysis. Women with intravenous tocolysis alone $(n=29)$ served as a reference group. The results showed that $P$ gel and placebo delayed PTB more effectivelythan intravenous tocolysis alone $(p<0.0001$ respectively). The composite neonatal morbidity and length of neonatal intensive care (NICU) were lower after $\mathrm{P}$ and placebo compared to the reference group $(p<0.0001$ respectively). We conclude, that maintenance treatment with vaginal P gel or placebo delayed PTB more efficiently than intravenous tocolysis alone, suggesting an effect of the placebo gel rather than of $P$. The acidic character of the placebo gel reinforced the physiological acidic barrier at the uterine cervix which protects the pregnancy from pathogen invasion and uterine infection leading to PTB.

\section{Introduction}


The global rate of PTB before 37 gestational weeks, the main cause of all neonatal, infant and child mortality up to 5 years age, is still 10\% (1). The multifactorial risk factors behind PTB include demographic and socioeconomic factors such as psychosocial stress, malnutrition, low and high maternal age, multiple pregnancy, decidual bleeding, and uterine infection (2-7). Current tocolytic treatments with an oxytocin receptor antagonist, a b2-adrenergic receptor agonist, magnesium sulfate, a NSAID or a calcium blocker do not prevent PTB, but aim to delay delivery for 48 hours to optimize the effect of antenatal corticosteroids for fetal lung maturation and allow for transport to a tertiary hospital with NICU expertise (8). A cervical length (CL) $\leq 25 \mathrm{~mm}$ at midgestation is regarded as a primary predictor for PTB (9).

Despite the multifactorial causes behind PTB, a cervical connective tissue remodeling precedes both preterm and term labor. This remodeling is chacterized by an increased density of macrophages in the cervical tissue, release of proinflammatory cytokines and prostaglandin $E$, a functional $P$ withdrawal, activation of metalloproteinase (MMP) enzymes, a changed proteoglycan composition, dispersion of collagen fibrils and collagen degradation, that allow for cervical effacement and dilatation $(4-7,10)$.

Although $P$ is regarded as the crucial hormone for pregnancy maintenance, the effect of prophylactic treatments with progestagens, i e bioidentical $P$ and synthetic progestins such as $17 a-$

hydroxyprogesterone caproate) to delay PTB are inconclusive (3). Bioidentical P has no androgenic effects that might affect the lipid metabolism or harm the fetus. In clinical practice, oral $P$ is poorly absorbed because of the liver metabolism, daily $\mathrm{P}$ injections would be painful, a transdermal $\mathrm{P}$ preparation has not been available in obstetrics, and vaginal treatments are therefore used (11). Prophylactic treatment with P from the second trimester in asymptomatic women with $\mathrm{CL} \leq 25 \mathrm{~mm}$, which is recommended by the International Federation of Gynecology and Obstetrics (FIGO), is effective according to some but not the largest studies $(2,12,13)$.

Extensive screening programmes are needed to evaluate prophylactic strategies since only $1 \%$ of asymptomatic women have a $\mathrm{CL} \leq 25 \mathrm{~mm}$ in the second trimester (14) and only $10-20 \%$ of women with spontaneous PTB have a previous PTB $(2,9)$. The objective of this study was therefore to investigate the efficacy of maintenance treatment with vaginal P gel or placebo in delaying PTB in women after the onset of preterm labor (PTL).

\section{Methods}

This trial was conducted at the Department of Women's and Children's Health, Karolinska University Hospital, Stockholm, Sweden between December 1, 2009 and January 31, 2018. Ethics approval was obtained from the Regional Ethics Board for Medical Sciences in Stockholm September 5, 2007, No 2007311-31. It was approved by the European Union Drug Regulating Authorities Clinical Trials (EudraCT) September 1, 2007, No 2007-003348-31 and by the Swedish Medical Products Agency May 15, 2008, No $151: 2008 / 30388$. 
PTL was uterine contractions $\geq 2 / 10$ min for $>30$ min monitored by cardiotocography (CTG), recorded in electronic obstetric records (Obstetrix ${ }^{\circledR}$ Cerner $A B$, Stockholm, Sweden) resulting in a short CL $<25 \mathrm{~mm}$ determined sonographically by a specialist in obstetrics and gynecology due to standardized criteria. In all years studied, intravenous tocolysis was a bolus dose of the oxytocin receptor antagonist atosiban (Tractocile $^{\circledR}$, Ferring Pharmaceuticals, Sweden) $6.75 \mathrm{mg}$ followed by infusion of $300 \mathrm{mg} / \mathrm{min}$ during 3 hours and thereafter $100 \mathrm{mg} / \mathrm{min}$ until 48 hours. Alternatively, the b2-adrenergic receptor agonist terbutaline (Bricanyl ${ }^{\circledR}$, AstraZeneca PLC, Great Britain) $5 \mathrm{mg} / \mathrm{mL}$ was given for 48 hours according to the individual physician's choice. All women received two doses of betamethasone (Betapred ${ }^{\circledR}$, Swedish Orphan Biovitrum AB) 12 mg intramuscularly 24 hours apart for fetal lung maturation. Prophylactic antibiotics were not given to women with intact fetal membranes. Intrapartal prophylaxis with benzylpenicillin $3 \mathrm{~g}$ every 6 hours was given during active labor before 37 gestational weeks.

\section{Study participants}

\section{Progesterone and placebo groups}

Healthy women with singleton pregnancy and PTL after 24 gestational weeks resulting in a CL $<25 \mathrm{~mm}$ were included after oral and written consent. Exclusion critera were ruptured fetal membranes, cervical dilatation, cervical cerclage, signs or symptoms of urogenital infection, previous uterine surgery, prophylactic progesterone treatment, intercurrent diseases, pregnancy complications such as preeclampsia or gestational diabetes, intrauterine fetal growth restriction or fetal malformations. The participants were blindly randomised by a computerized system using closed envelopes to additional treatment with daily vaginal P gel (Crinone ${ }^{\circledR} 90$ mg/dose, Merck KGaA, Germany) or placebo gel (Replens ${ }^{\circledR}$, CampusPharma $A B$, Sweden) started after intravenous tocolysis. The maintenance treatment with $P(n=29)$ or placebo $(n=29)$ continued until 34 weeks, rupture of the fetal membranes or delivery whatever occurred first. It was not possible to blind the gel packages due to practical reasons. Thus, a semi-blinded design was obtained where the randomization process was blinded but not the treatments. All women were seen weekly by an obstetrician at the hospital after discharge.

\section{Reference group}

Healthy women $(n=29)$ with singleton pregnancy, intact fetal membranes and PTL after 24 gestational weeks resulting in a $\mathrm{CL}<25 \mathrm{~mm}$ with identical inclusion and exclusion criteria who received intravenous tocolysis alone during the same years were identified retrospectively to serve as a reference group. Ethics approval for this part of the study was obtained from the Regional Ethics Board for Medical Sciences in Stockholm April 9, 2015, No 2014/255-31. Individual patient consent was not requested, since all data were anonymized and presented on a group basis only.

\section{Statistical analysis}

Based on results from previous studies (15) we hypothesized that $P$ would delay the latency to delivery by $30 \%$ compared to placebo. According to a power analysis, a sample size of $n=29$ in each group would be 
needed when aiming at a significance of $5 \%$ and power of $80 \%$ (16). Continuous data were analyzed using Mann Whitney U-test and General Linear Model when appropriate and categorical data with $\mathrm{Chi}^{2}{ }^{2}$ test and Fisher's exact test when appropriate. Composite neonatal morbidity was analyzed with One way ANOVA. Continuous data were presented as mean \pm standard deviation (SD) and categorical data as numbers and percentages. A two-tailed $p$ value $<0.05$ was considered significant.

\section{Results}

The randomization process is shown in Figure 1. The study character as a single center study with an aim to include the limited rate of $<1 \%$ of all delivering women with early PTL between $24+0-27+6$ weeks with the mentioned strict inclusion and exclusion criteria explains the duration of the study.

The primary outcome latency to delivery was calculated from the first $\mathrm{P}$ or placebo dose and from the start of intravenous tocolysis in the reference group. Secondary outcomes were early PTB $<34$ weeks, late PTB $<37$ weeks, birth weight (BW), composite neonatal morbidity and length of NICU stay. Composite neonatal morbidity was Apgar score $<7$ at $5 \mathrm{~min}$, the incidence of neonatal respiratory distress syndrome (RDS), intraventricular hemorrage (IVH), necrotizing enterocolitis (NEC), and sepsis $\leq 7$ days, taken together with retinopathy of the newborn (ROP) and neonatal death during the NICU stay. Neonatal RDS was defined by clinical diagnosis of type I respiratory distress syndrome and a requirement of oxygen therapy for at least 24 hours. Maternal adverse effects such as fatigue, headache, or intrahepatic cholestasis were monitored.

Maternal data are shown in Table 1. Demographic data were comparable between the groups. The participants in all groups had a medical history of a previous PTB in $25 \%$ or a first or second trimester miscarriage in $25 \%$. The circulating level of the inflammatory marker C-reactive protein (CRP) at inclusion was mean $<10 \mathrm{mg} / \mathrm{L}$ and comparable between the groups (data not shown). The mean gestational age at inclusion in all groups was 26 weeks with $82 \%$ of women included between $24+0-27+6$ weeks and $8 \%$ between $28+0-31+6$ weeks. The CL (mean at inclusion was

The latency to delivery (mean \pm SD) was $58 \pm 34$ days in the P group, $64 \pm 51$ days in the placebo group $(p=0.83)$ and $2 \pm 2$ days in the reference group ( $P$ and placebo $v s$ reference both $p<0.0001)$. The compliance rates were high. One participant in the $\mathrm{P}$ and placebo groups had their treatments interrupted before 34 weeks after referral to another hospital and gave birth after 37 weeks. One woman in the $P$ group who had an emergency cervical cerclage on maternal request after inclusion continued her $P$ treatment and gave birth at 34 weeks. No cases of severe maternal headache or intrahepatic cholestasis were reported.

Neonatal data are shown in Table 2. The rate of early PTB $<34$ weeks was $34 \%$ in the P group, $38 \%$ in the placebo group $(p=0.32)$ and $100 \%$ in the reference group ( $P$ vs reference $p=0.01$, placebo $v s$ reference $p$ $=0.02)$. The rate of late PTB $<37$ weeks was $52 \%$ in the P group, $45 \%$ in the placebo group $(p=0.65)$ and $100 \%$ in the reference group ( $P$ vs reference $p=0.06$ and placebo $v s$ reference $p=0.04$ ). The BW mean \pm 
SD) was $2471 \pm 1078 \mathrm{~g}$ in the P group, $2452 \pm 1054$ in the placebo group $(\mathrm{p}=0.84)$ and $1023 \pm 409 \mathrm{~g}$ in the reference group ( $P$ and placebo $v s$ reference both $p<0.0001)$. The composite neonatal morbidity was $11 \%$ in the $P$ group, $9 \%$ in the placebo group $(p=0.65)$ and $28 \%$ in the reference group ( $P$ and placebo $v s$ reference $p<0.0001)$. The mean length of NICU stay was 10 days in both $P$ and placebo groups compared to 70 days in the reference group $(P$ and placebo $v s$ reference $p<0.0001)$. During the NICU stay two neonatal deaths occurred in the $\mathrm{P}$ group, one in the placebo group and two in the reference group. These neonatal deaths were caused by postnatally diagnosed severe malformations and chromosomal aberrations and were not associated with the different treatments.

\section{Discussion}

We have evaulated the efficacy of maintenance treatment with vaginal P gel or placebo in delaying PTB in women after the onset of PTL. The maintenance treatments were initiated after standard intravenous tocolysis, and women who received intravenous tocolysis alone served as a reference group.

\section{Main findings}

The main finding was that the latency to delivery was comparable after maintenance treatment with $\mathrm{P}$ gel or placebo, but longer in these groups compared to the reference group. Likewise, the rate of early PTB < 34 weeks was lower after maintenance treatment with $\mathrm{P}$ or placebo compared to the reference group. Furthermore, neonates in the $\mathrm{P}$ and placebo groups had higher BW, lower composite morbidity, and shorter length of NICU stay compared to the reference group. The $\mathrm{P}$ and placebo treatments were safe with regard to maternal, fetal and neonatal health in a short perspective, since no severe adverse effects were recorded among the participating women or their neonates until discharge from the hospital.

\section{Clinical implications}

The comparable efficacy of maintenance treatment with P gel or placebo in delaying PTB suggested that properties of the placebo rather than of P delayed PTB. The placebo gel is an acidic emulsion of oil and water. An acidic milieu with a low $\mathrm{pH}<4.5$ at the uterine cervix constitutes a barrier against ascending pathogen invasion from the skin and bowel microbiome, and the vaginal microbiome undergoes significant changes during pregnancy resulting in a decrease in the vaginal $\mathrm{pH}$ (17). Thus, the placebo gel reinforced the physiological barrier at the uterine cervix which protects the pregnancy against pathogen invasion and uterine infection. The present results were in accordance with reports on uterine infection due to pathogen invasion from the skin and gastrointestinal microbiome as an ethiology behind $30-60 \%$ of all early PTB (2). The present results were also in agreement with results from an experimental study showing that the placebo gel exerts anti-inflammatory effects, decreases MMP-13, and delays PTB (18).

Randomized studies on maintenance treatment with vaginal P compared to placebo after intravenous tocolysis are warranted (19). Of the few published reports on this topic, two trials report longer latency do delivery after $P$ compared to no treatment $(15,20)$, one trial reports longer latency to delivery after $P$ 
compared to placebo (21), and one trial reports no reduction in PTB after vaginal P or intramuscular 17ahydroxyprogesterone caproate compared to no treatment (22). The discrepancies between the present results and previous reports could be explained by the different study designs regarding gestational age at inclusion, method for CL estimation and mode of treatment. Participants in the present trial were included at mean 26 weeks in contrast to mean > 31 weeks $(15,20-21)$ and $63 \% \geq 28$ weeks (22). Preterm labor was uterine contractions $\geq 2 / 10$ min for more than 30 min resulting in a sonographically determined $\mathrm{CL}<25 \mathrm{~mm}$ without dilatation in the present trial and one previous report (22), in contrast to cervical shortening and/or softening or dilatation (15), cervical softening, shortening at least by $50 \%$ and dilatation $<2 \mathrm{~cm}$ (20) or cervical dilatation and/or effacement (21) as determined by digital examination. Transvaginal sonography is recommended for CL assessment in women with PTL, and the accuracy of digital estimation is questioned (23). Intravenous tocolysis in the present trial was an oxytocin receptor antagonist or a b2-receptor agonist in contrast to magnesium sulfate in combination with ampicillin (15), a b2-receptor agonist (20), magnesium sulfate in combination with pethidine and ampicillin (21), an oxytocin receptor agonist, a calcium blocker or a NSAID (22) in previous reports. The $\mathrm{P}$ treatment in the present trial was vaginal P gel $90 \mathrm{mg}$, in contrast to P suppositories $400 \mathrm{mg}(15)$ or $200 \mathrm{mg}(21-23)$ in previous reports.

\section{Strengths And Limitations}

Strengths of this study were its randomized controlled design, the single center character, the strict inclusion and exclusion critería and that all data were retrieved from original obstetric records.

Limitations were the lack of double blinded design and the limited sample size, although it was adequate according to a power analysis for the primary outcome. Also, the mere enrolment to the maintenance treatment could have reduced the risk of PTB by reducing psychosocial stress $(24,25)$.

\section{Research implications}

The present results emphasize the importance of further studies not only on maintenance treatment with $\mathrm{P}$ but also on treatment with non-hormonal agents that strengthen the physiological barrier at the uterine cervix against pathogen invasion and uterine infection.

\section{Conclusion}

The present results showed that maintenance treatment with vaginal P gel or placebo delayed PTB more efficiently than intravenous tocolysis alone in women after the onset of PTL, suggesting rhar this was an effect of the placebo gel rather than of $P$. We conclude, that the placebo gel reinforced the physiological acidic barrier at the uterine cervix which protects the pregnancy from pathogen invasion and uterine infection leading to PTB.

\section{List Of Abbreviations}


Birth weight (BW), Cervical length (CL), Cardiotocography (CTG), International Federation of Gynecology and Obstetrics (FIGO), Intraventricular Hemorrage (IVH), Matrix Metalloproteinase (MMP), Necrotizing Enterocolitis (NEC), Neonatal Intensive Care Unit (NICU), Non-steroidal Anti-Inflammatory Drug (NSAID), Preterm birth (PTB), Preterm labor (PTL), Progesterone (P), Respiratory Distress Syndrome (RDS), Retinopathy of the Newborn (ROP), Standard Deviation (SD).

\section{Declarations}

\section{Acknowledgements}

We thank Therese Westerberg, nurse at the Neonatal Unit, for retrieving neonatal data, professor Lars Hagenäs, Endocrinology Unit, Astrid Lindgren's Children's Hospital for valuable comments when planning this study, all women who participated, the staff at the Obstetric, Neonatal and Operative Units at the Karolinska University Hospital for constructive collaboration, and Dr Tomislav Vladic for statistical advice and comments on the manuscript.

\section{Author Contribution}

Both authors (GM, YVS) planned and designed the study, collected the material, analysed the data, wrote and approved the manuscript.

\section{Competing Interests}

The authors declare that they have no competing interests.

\section{Consent for Publication}

Not applicable.

\section{Data Availability}

All data are preserved by the authors and available if requested.

\section{Ethics statement}

Ethics approval for the randomized trial was obtained from the Regional Ethics Board for Medical Sciences in Stockholm September 5, 2007, No 2007-311-31. It was approved by the European Union Drug Regulating Authorities Clinical Trials (EudraCT) September 1, 2007, No 2007-003348-31and by the Swedish Medical Products Agency May 15, 2008, No 151:2008/30388. Ethics approval for the retrospective part of the study was obtained from the Regional Ethics Board for Medical Sciences in Stockholm April 9, 2015, No 2014/255-31.

\section{Funding}

There was no funding. 


\section{References}

1. Chawanpaiboon S, Vogel JP, Moller AB, Lumbiganon P, Petzold M, Hogan D, et al. Gloval, regional and national estimates of levels of preterm birth in 2014: a systematic review and modeling analysis. The Lancet Global Health 2019;vol 7, E37 46.

2. Cobo T, Kacerovsky M, Jacobsson B. Risk factors for spontaneous preterm birth. Int J Obstet Gynecol 2020; 150: 17-23.

3. Norman J. Progesterone and preterm birth. Obstet Gynecol 2020; 150: 24-30.

4. Vladic-Stjernholm Y Wang H, Stygar D, Ekman G, Sahlin L. Differential regulation of the progesterone receptor A and B in the human uterine cervix at parturition. Gynecol Endocrinol 2004;Jan18(1):41-6.

5. Abelin-Törnblom S, Dubicke A, Byström B, Chromek M, Brauner A, Ekman-Ordeberg G. Non-infected preterm parturition is related to increased concentrations of IL-6, IL-8 and MCP-1 in human cervix. J Reprod Biol Endocrinol 2005; 3:39.

6. Dubicke M, Ekman-Ordeberg G, Mazurek P, Miller L,Yellon SM. Density of stromal cells and macrophages associated with collagen remodeling in the human cervix in preterm and term birth. $J$ Reprod Sci 2016;23:595-603.

7. Yellon SM, Dobyns AE, Beck HL, Kurtzmans JT, Garfield RE. Kirby MA. Loss of progesterone receptormediated actions induce preterm cellular and structural remodeling of the cervix and premature birth. PLoS ONE 2013;8(12): e81340.

8. Haas DM, Benjamin T, Sawyer R, Quinney SK. Short-term tocolytics for preterm delivery - current perspectives. International Journal of Women's Health 2014; 6 343-9.

9. lams JD, Goldenberg RL, Meis PJ, Mercer B, Moawad A, Das A, et al. The length of the cervix and the risk of spontaneous preterm delivery. National Institute of Child Health and Human Development Maternal Fetal Medicine. New Engl J Med 1996;334:567-72.

10. Vladic-Stjernholm Y, Stygar D, Månsson C, Masironi B, Åkerberg S, Ekman G, et al. Factors involved in the inflammatory events of cervical ripening in humans. J Reprod Biol Endocrinol 2004;2:74.

11. Schindler AE, Campagnoli C, Druckmann R, Huber J, Pasqualini JR, Schweppe KW, et al. Classification and pharmacology of progestins. Maturitas 2008;61:171-80.

12. Norman JE, Marlow N, Messow CM, Shennan A, Bennett P, Thornton P, et al. Vaginal progesterone prophylaxis for preterm birth (the OPPTIMUM study): a multicentre, randomised, double-blind study. Lancet 2016;387:2106-16. 
13. FIGO Working Group on best practice in maternal-fetal medicine. Best practice in maternal-fetal medicine. Int J Gynecol Obstet 2015:128:80-2.

14. Kuusela P, Jacobsson B, Söderlund M, Bejlum C, Almström E, Ladfors L, et al. Transvaginal sonographic evaluation of cervical length in the second trimester of asymptomatic singleton pregnancies, and the risk of preterm delivery. Acta Obstet Gynecol Scand 2015;94:598-607.

15. Borna S, Sahabi N. Progesterone for maintenance tocolytic therapy after threatened preterm labour: A randomised controlled trial. Austr New Zeal J Obstet Gynecol 2008;48:58-63.

16. Pocock SJ. Clinical trials (1984). Wiley \& Sons, New York, US.

17. Nuriel-Ohayon $\mathrm{M}$, Neuman $\mathrm{H}$, Koren $\mathrm{O}$. Microbial changes during pregnancy, birth, and infancy. Front Microbiol 2016;7:1031

18. Nold C, Jensen T, O'Hara K, Stone J, Yellon SM, Vells AT. Replens prevents preterm birth by decreasing type I interferon strengthening of the cervical epithelial barrier. Am J Reprod Immunol 2019;00:e13192.

19. Su L, Samuel M, Chong Y. Progestational agents for treating threatened or established preterm labour. Cochrane Database Syst Rev 2014, Issue 1. Art. No.: CD006770.

20. Arikan I, Barut A, Harma M, Harma IM. Effect of progesterone as a tocolytic and in maintenance therapy during preterm labor. Gynecol Obstet Invest 2011;72:269-73.

21. Sharami SH, Zahiri Z, Shakiba M, Milani F. Maintenance therapy by vaginal progesterone after threatened idiopatic preterm labor: a randomized placebo-controlled double-blind trial. Int J Fertil Steril 2010;4:45-50.

22. Facchinetti F, Vergani P, Di Tommaso M, Marozio M, Acaia B, Vicini R, et al. Progestogens for maintenance tocolysis in women with a short cervix: a randomized controlled rrial. Obstet Gynecol 2017;130(1):64-70.

23. Reiter E, Aagard Nielsen K, Fedder J. Digital examination and transvaginal scan - competing or complementary for predicting preterm birth? Acta Obstet Gynecol Scand 2012;91:428-38.

24. McCambridge J, Witton J, Elbourne DR. Systematic review of the Hawthorne effect: new concepts are needed to study research participation effects. J Clin Epidemiol 2014;67:267-77.

25. Shapiro G, Fraser W, Frasch, Séquin J. Psychological stress in pregnancy and preterm birth: associations and mechanisms. J Perinat Med 2013;41:631-45.

\section{Tables}


Table 1. Maternal data. Statistical methods Mann Whitney U-test and General Linear Model when appropriate ${ }^{1}$, Chi ${ }^{2}$-test and Fisher's exact test ${ }^{2}$.

\begin{tabular}{|c|c|c|c|c|c|c|}
\hline Variable & Progesterone (P) & Placebo (PI) & Reference (R) & P vs Pl & P vs R & Pl vs $\mathrm{R}$ \\
\hline & $h=29$ & $\mathrm{n}=29$ & $\mathrm{n}=29$ & $\mathrm{p}$ value & $\mathrm{p}$ value & $\mathrm{p}$ value \\
\hline Age, years (mean $\pm \mathrm{SD})$ & $31 \pm 4$ & $29 \pm 6$ & $32 \pm 5$ & $0.03^{1}$ & $0.53^{1}$ & $0.01^{1}$ \\
\hline $\mathrm{BMI}, \mathrm{kg} / \mathrm{m}^{2}($ mean $\pm \mathrm{SD})$ & $24 \pm 5$ & $23 \pm 3$ & $24 \pm 2$ & $0.65^{1}$ & $0.55^{1}$ & $0.05^{1}$ \\
\hline Primiparous, $\mathrm{n}(\%)$ & $12(44)$ & $16(55)$ & $16(55)$ & $0.42^{2}$ & $0.42^{2}$ & $0.99^{2}$ \\
\hline $\mathrm{GA}$, weeks $\pm \mathrm{d}$ (mean) & $26 \pm 12$ & $26 \pm 17$ & $26 \pm 15$ & $0.66^{1}$ & $0.26^{1}$ & $0.65^{1}$ \\
\hline $\mathrm{CL}, \mathrm{mm}($ mean $\pm \mathrm{SD})$ & $11 \pm 5$ & $12 \pm 5$ & $14 \pm 7$ & $0.37^{1}$ & $0.04^{1}$ & $0.24^{1}$ \\
\hline Atosiban/terbutaline, $\mathrm{n}(\%)$ & $23 / 4(85 / 15)$ & $26 / 3(90 / 10)$ & $26 / 3(90 / 10)$ & $0.61^{2}$ & $0.95^{2}$ & $0.99^{2}$ \\
\hline Latency, days (mean $\pm \mathrm{SD}$ ) & $58 \pm 34$ & $64 \pm 51$ & $2 \pm 2$ & $0.83^{1}$ & $<0.0001^{1}$ & $<0.0001^{1}$ \\
\hline
\end{tabular}

Abbreviations: $\mathrm{BMI}=$ body mass index, $\mathrm{CL}=$ cervical length at inclusion, $\mathrm{GA}=$ gestational age at inclusion, Latency $=$ latency to delivery .

Table 2. Neonatal data. Statistical methods Mann Whitney U-test ${ }^{1}$, Chi ${ }^{2}$-test and Fisher's exact test when appropriate ${ }^{2}$, and One Way ANOVA ${ }^{3}$.

\begin{tabular}{|c|c|c|c|c|c|c|}
\hline Variable & $\begin{array}{l}\text { Progesterone (P) } \\
\mathrm{n}=29\end{array}$ & $\begin{array}{l}\text { Placebo (PI) } \\
\mathrm{n}=29\end{array}$ & $\begin{array}{l}\text { Reference (R) } \\
n=29\end{array}$ & $\begin{array}{l}\mathbf{P} \text { vs } \mathbf{P I} \\
\mathrm{p} \text { value }\end{array}$ & $\begin{array}{l}\mathbf{P} \text { vs } \mathbf{R} \\
\mathrm{p} \text { value }\end{array}$ & $\begin{array}{l}\text { PI vs } \mathbf{R} \\
\text { p value }\end{array}$ \\
\hline PTB $<34$ weeks, $n(\%)$ & $9(34)$ & $11(38)$ & $29(100)$ & $0.32^{2}$ & $0.01^{2}$ & $0.02^{2}$ \\
\hline PTB $<37$ weeks, n (\%) & $15(52)$ & $13(45)$ & $29(100)$ & $0.65^{2}$ & $0.06^{2}$ & $0.04^{2}$ \\
\hline $\mathrm{BW}, \mathrm{g}($ mean $\pm \mathrm{SD})$ & $2471 \pm 1078$ & $2452 \pm 1054$ & $1023 \pm 409$ & $0.84^{1}$ & $<0.0001^{1}$ & $<0.0001^{1}$ \\
\hline Composite morbidity, $\mathrm{n}(\%)$ & $21(11)$ & $19(9)$ & $57(28)$ & $0.65^{3}$ & $<0.0001^{3}$ & $<0.0001^{3}$ \\
\hline NICU stay, days (mean \pm SD) & $10 \pm 25$ & $10 \pm 21$ & $70 \pm 40$ & $0.59^{1}$ & $<0.0001^{1}$ & $<0.0001^{1}$ \\
\hline
\end{tabular}

Abbreviations: $\mathrm{BW}=$ birth weight, Compsite, morbidity $=$ Apgar $<7$ at $5 \mathrm{~min}$, intraventricular hemorrage, necrotizing enterocolitis, respiratory distress syndrome, and sepsis $\leq 7$ days, taken together with retinopathy of the newborn and death during the NICU stay. NICU = Neonatal Intensive Care Unit, PTB = preterm birth.

\section{Figures}




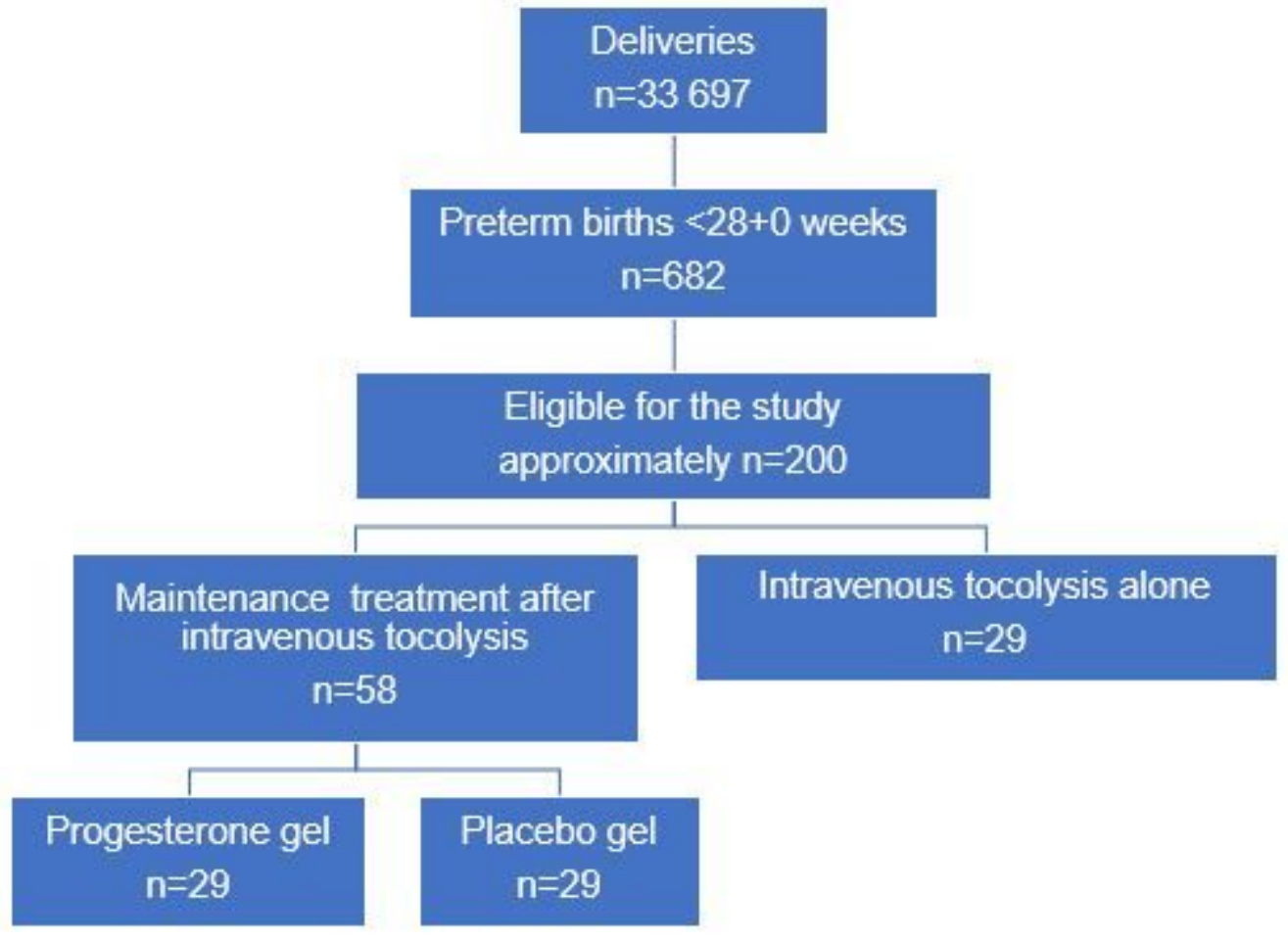

Figure 1

Patient enrolment between December 1, 2009 and January 31, 2018. 